\title{
Can intramuscular corticosteroid injection cause nonarteritic anterior ischemic optic neuropathy?
}

This article was published in the following Dove Press journal:

Clinical Ophthalmology

25 March 2013

Number of times this article has been viewed

\section{Berker Bakbak \\ Banu Turgut Ozturk \\ Sansal Gedik \\ Bengu Ekinci Koktekir \\ Saban Gonul}

Selcuk University Medical Faculty, Department of Ophthalmology, Konya, Turkey
Correspondence: Berker Bakbak

Selcuk University Faculty of Medicine,

Department of Ophthalmology,

42075, Konya, Turkey

Fax +90332 24I 2184

Email drberkerbakbak@yahoo.com

\begin{abstract}
A 56-year-old man noted a sudden decrease of vision in his right eye 4 hours after intramuscular triamcinolone acetonide (TA) injection. A diagnosis of unilateral nonarteritic anterior ischemic optic neuropathy (NAION) was made, and the patient was counseled to discontinue using TA. Examination for possible risk factors revealed controlled hypertension. Final visual acuity was finger counting at $1 \mathrm{~m}$, and the optic disc was pale in his right eye. This is the first reported case of unilateral NAION that has occurred in a patient after intramuscular corticosteroid injection. Although a cause-and-effect relationship is difficult to prove, the short duration between the TA injection and the NAION is noteworthy. The history of corticosteroid injection should be questioned in cases with predisposing conditions such as hypertension.
\end{abstract}

Keywords: ischemic optic neuropathy, corticosteroids, optic disc edema

\section{Introduction}

Nonarteritic anterior ischemic optic neuropathy (NAION) is the most common form of acute optic neuropathy in people over the age of 50 years. The exact pathophysiology remains unclear; however, transient hypoperfusion of the optic nerve head circulation and embolic lesions of the arteries/arterioles feeding the optic nerve head are the most common causes of NAION. ${ }^{1}$ Risk factors include systemic hypertension, nocturnal hypotension, diabetes mellitus, ischemic heart disease, hyperlipidemia, atherosclerosis, and optic disc pathologies like a small cup-to-disc ratio and optic nerve head drusen. Various drugs, including phosphodiesterase type 5 inhibitors and interferon-alpha, have also been implicated in the development of NAION; however, there has been no report of NAION attributed to corticosteroids. In contrast, its administration has been recently recommended for the improvement of vision. ${ }^{1-3}$

\section{Case report}

A 56-year-old male complained of acute decreased vision in his right eye. He also had a history of a lumbar herniated disc, for which he was prescribed triamcinolone acetonide (TA; Kenacort Retard 40 mg, Bristol-Myers Squibb, New York, NY, USA). Four hours after intramuscular injection of his first dose of TA, the patient noted a sudden and profound decrease of vision in his right eye. In the neuroophthalmologic examination on the next day, best-corrected visual acuity was finger counting at $1 \mathrm{~m}$ in the right eye and 20/20 in the left eye accompanied by an afferent pupillary defect in the right eye. Intraocular pressures were $14 \mathrm{mmHg}$ in both eyes. Slit-lamp examination was unremarkable. A dilated fundus examination of the right eye revealed prominent swelling of the disc with a disc rim hemorrhage. Dilated fundus 
examination of the left eye revealed a healthy but crowded disc with a cup-to-disc ratio of 0.2 (Figure 1). Testing with a Humphrey Visual Field Analyzer ${ }^{\circledR}$ (Carl Zeiss Meditech AG, Jena, Germany) showed an absolute defect in the right eye (Figure 2). Fluorescein angiography revealed hyperfluorescence of the right optic disk and leakage from it, indicating edema (Figure 3).

The patient's medical history revealed a 7-year history of hypertension treated with captopril $25 \mathrm{mg}$ (Kapril ${ }^{\circledR}$; MN Pharmaceuticals, Istanbul, Turkey). The arterial pressure at the time of examination was 130/90 $\mathrm{mmHg}$. The patient stated that he had unstable hypertension and that he had not been examined for many years; therefore, the information regarding the long-term blood pressure data from the last several years cannot be provided. He reported no symptoms of arteritic anterior ischemic optic neuropathy, including painful jaw, muscle spasms, scalp tenderness, or shoulder pain. Results of laboratory tests, including complete blood count, erythrocyte sedimentation rate, and serum C-reactive protein, were within normal range. A systemic evaluation was performed by a physician, and with the exception of senile hypertension, there was no evidence of cardiovascular disease, hypotension, diabetes, or hyperlipidemia. A diagnosis of unilateral NAION was made, and the patient was counseled to discontinue using TA. Three months later, visual acuity was finger counting at $1 \mathrm{~m}$ and the optic disc was pale in $\mathrm{OD}$.

\section{Discussion}

Though hypertension may alone precipitate an NAION, the short duration between the TA injection and the visual loss raises a fair question about a relationship of these factors in our patient.

TA is a synthetic fluorinated corticosteroid that has antiinflammatory, antipruritic, and vasoconstrictive properties. To our knowledge, synthetic corticosteroids are more potent than natural corticosteroids and have a longer duration of action. ${ }^{4,5}$ Additionally, when given intramuscularly,

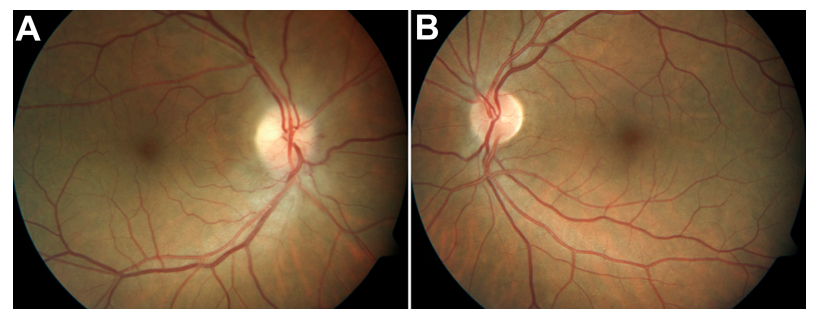

Figure I (A) Fundus photograph of the right eye shows swelling of the disc and disc rim hemorrhage (left). (B) Fundus photograph of the left eye shows a healthy appearing but crowded disc with a cup-to-disc ratio of 0.2 (right).

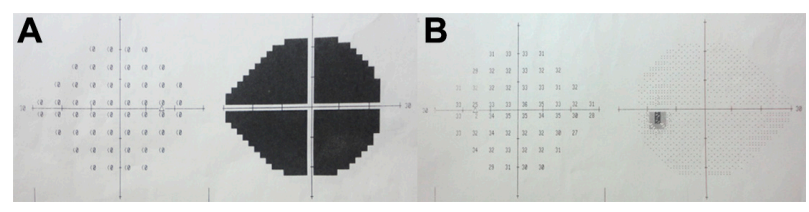

Figure 2 Humphrey 24-2 visual field of the right and the left eyes at the initial examination. (A) Right eye; (B) left eye.

synthetic corticosteroids are absorbed much more rapidly from the injection site. ${ }^{6}$ In a study by Derendorf et al, ${ }^{7}$ plasma levels of TA after $5 \mathrm{mg}$ of oral administration of TA achieved a maximum level of $10.5 \mathrm{ng} / \mathrm{mL}$ after 1 hour. Regarding this finding, we may speculate that the intramuscularlyadministered triamcinolone was able to enter the circulatory system in this short period of time.

The injection of TA might have an effect on optic nerve circulation by the following possible mechanisms. First, the impaired optic nerve circulation is related to the inhibition of nitric oxide synthesis. Nitric oxide, known as a physiological vasodilator, is synthesized in vascular endothelial cells. Corticosteroids reduce its synthesis by altering the glucocorticoid receptor, which has been identified in endothelial cells. ${ }^{8}$ Thus, impaired endothelium-dependent dilation may result in vasoconstriction of the arteries/arterioles that feed the optic nerve head, thus decreasing the optic nerve circulation. Second, an acute increase in vascular tone might be apparent. Corticosteroids raise the vascular tone by potentiating the effects of vasoconstrictor hormones and by acting directly on vascular smooth muscle cells. ${ }^{9}$ Corticosteroids also enhance agonist-mediated pharmacomechanical coupling by increasing $\mathrm{Ca}^{2}$ mobilization and $\mathrm{Ca}^{2+}$ sensitivity of myofilaments. ${ }^{8}$ These vascular changes have been shown to develop within

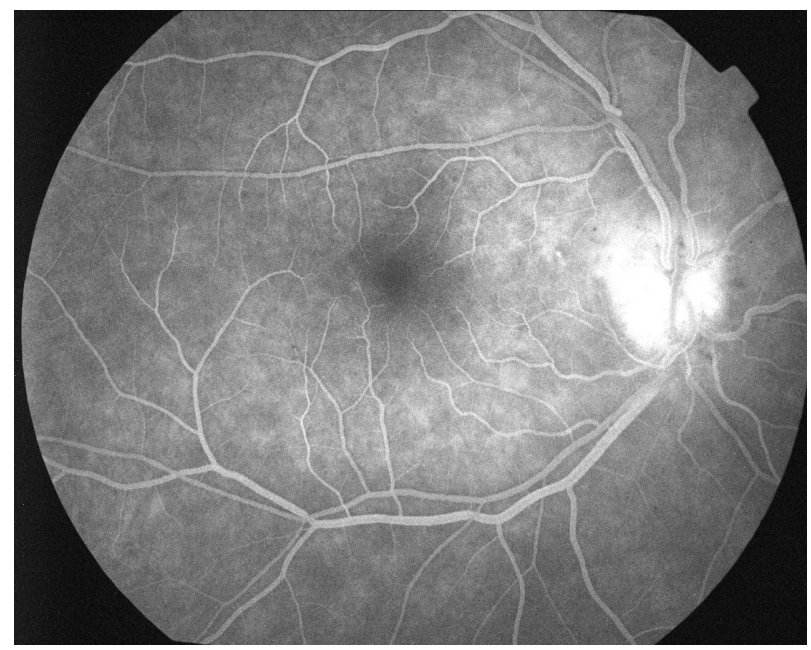

Figure 3 Fluorescein angiography shows diffuse leakage of the optic disc in the late phase. 
hours to days. In experimental studies regarding the time course for corticosteroids to potentiate vascular tone, rapid responses - by activation of the sodium-proton exchanger, stimulation of inositol phosphates, and cytosolic calcium mobilization - have been shown in cultured vascular smooth muscle cells. ${ }^{10}$ Third, since the patient is already known to have arterial hypertension, an acute hypertensive peak secondary to corticosteroid administration may have occurred. Fourth, this may have been an incidental occurrence; even though NAION developed 4 hours after corticosteroid injection, it may have occurred incidentally on the grounds of unstable hypertension. Since the systemic status of the patient before the visual loss is unknown, an increase in the $\mathrm{R}-\mathrm{R}$ interval may have also caused NAION, particularly in cases with hypertension.

No treatment has been proven to reverse the course of NAION. Hayreh ${ }^{1}$ recently reported that systemic corticosteroid therapy given during the acute phase of NAION significantly improved visual acuity and the visual field by leading to the faster resolution of optic disc edema. In contrast, our case suggested that synthetic corticosteroids may precipitate the development of a NAION as well.

Although it is a unique case and there is no certain evidence about the relationship between TA and NAION, the short duration between TA injection and NAION is noteworthy. In this regard, the history of corticosteroid injections should be questioned in cases of NAION.

\section{Disclosure}

The authors report no conflicts of interest in this work.

\section{References}

1. Hayreh SS. Ischemic optic neuropathy. Prog Retin Eye Res. 2009;28(1): 34-62.

2. Bollinger K, Lee MS. Recurrent visual field defect and ischemic optic neuropathy associated with tadalafil rechallenge. Arch Ophthalmol. 2005;123(3):400-401.

3. Gupta R, Singh S, Tang R, Blackwell TA, Schiffman JS. Anterior ischemic optic neuropathy caused by interferon alpha therapy. Am J Med. 2002;112(8):683-684.

4. Cevc G, Blume G. Biological activity and characteristics of triamcinolone-acetonide formulated with the self-regulating drug carriers, Transfersomes. Biochim Biophys Acta. 2003;1614(2): 156-164.

5. Kusama M, Sakauchi N, Kumaoka S. Studies of plasma levels and urinary excretion after intramuscular injection of triamcinolone acetonide. Metabolism. 1971;20(6):590-596.

6. Möllmann H, Rohdewald P, Schmidt EW, Salomon V, Derendorf H. Pharmacokinetics of triamcinolone acetonide and its phosphate ester. Eur J Clin Pharmacol. 1985;29(1):85-89.

7. Derendorf H, Hochhaus G, Rohatagi S, et al. Pharmacokinetics of triamcinolone acetonide after intravenous, oral, and inhaled administration. J Clin Pharmacol. 1995;35(3):302-305.

8. Ramot Y, Nyska A. Drug-induced thrombosis - experimental, clinical, and mechanistic considerations. Toxicol Pathol. 2007;35(2): 208-225.

9. Ullian ME. The role of corticosteriods in the regulation of vascular tone. Cardiovasc Res. 1999;41(1):55-64.

10. Wehling M, Neylon CB, Fullerton M, Bobik A, Funder JW. Nongenomic effects of aldosterone on intracellular $\mathrm{Ca} 2+$ in vascular smooth muscle cells. Circ Res. 1995;76(6):973-979.
Clinical Ophthalmology

\section{Publish your work in this journal}

Clinical Ophthalmology is an international, peer-reviewed journal covering all subspecialties within ophthalmology. Key topics include: Optometry; Visual science; Pharmacology and drug therapy in eye diseases; Basic Sciences; Primary and Secondary eye care; Patient Safety and Quality of Care Improvements. This journal is indexed on

Submit your manuscript here: http://www.dovepress.com/clinical-ophthalmology-journal

\section{Dovepress}

PubMed Central and CAS, and is the official journal of The Society of Clinical Ophthalmology (SCO). The manuscript management system is completely online and includes a very quick and fair peer-review system, which is all easy to use. Visit http://www.dovepress.com/ testimonials.php to read real quotes from published authors. 